\title{
GMO long-term effects: Relevance of environmental risk assessment
}

\author{
J. Kiss \\ Szent Istvan University, Godollo, Hungary \\ Correspondence to: Prof. Dr. Jozsef Kiss, Plant Protection Institute, Szent Istvan University, \\ H-2100 Godollo, Pater K. street 1, Hungary, E-mail: jozsef.kiss@mkk.szie.hu
}

Long-term effects originating from the cultivation of genetically modified plants are widely discussed in public and scientific debates. There is concern that potential long-term effects have not been sufficiently studied, experience is missing, and even suitable research methods might still not be available.

The Council Directive 2001/18/EC puts in place a step-bystep approval process made on a case-by-case assessment of the risk. The step-by-step principle means that the containment of GMOs is reduced and the scale of release increased gradually, but only if assessment of the earlier steps indicates that the next step can be taken.

The environmental risk assessment is based (among others) on results from experimental releases in representative receiving environment. The environmental risk assessment also covers the issue, whether the potential manifestation of adverse environmental effects can be predicted in the long term, and whether extrapolation of data from small to large-scale use is possible. Scientific knowledge and experience gained from growing GM crops during field trial and cultivation monitoring together with provisional approval periods for GM crops will also inform the risk assessment process and are opportunities to continually update environmental risk assessments in the light of any new knowledge (EFSA Guidance Document, 2006).

Is the present environmental risk assessment appropriate to identify long-term environmental risks and contribute to the development of proper risk management strategies?

Some long-term risks and their possible management frame will be discussed in the presentation.

\section{Literature}

EFSA Guidance Document (2006)Guidance document of the Scientific Panel on Genetically Modified Organisms for renewal of authorisations of existing GMO products lawfully placed on the market, notified according to Articles 8 and 20 of Regulation (EC) No 1829/2003. EFSA J 435:1-4.

Directive 2001/18/EC of the European Parliament and of the Council on the deliberate release into the environment of genetically modified organisms and repealing Council Directive 90/220/ EEC. Official J European Communities 17.04.2001, p. No L 106/1

To access this journal online:

http://www.birkhauser.ch/JVL 